\title{
A NEW COLONIAL ANELOSIMUS SPIDER FROM SURINAME (ARANEAE: THERIDIIDAE)
}

\author{
By Herbert W. Levi' ${ }^{1}$ and Deborah R. R. Smith ${ }^{2}$
}

Until recently, only a few colonial spiders were known. The recent increase in field work in the tropics revealed a number of new colonial species (Buskirk, 1981). Some of these colonial spiders belong to the theridiid genera Anelosimus and Achaearanea. The genus Anelosimus in America was revised by Levi, 1956, and the knowledge updated in 1963 and 1972, with new species described in 1967 and 1979. Those Anelosimus species known to be colonial are: $A$. studiosus, A. eximius, $A$. rupununi and $A$. lorenzo. Another species has now been found in Suriname. While reexamining some of the related species in preparation for this description, it was found that the synonymy of $A$. jabaquara Levi 1956 with $A$. dubiosus (Keyserling, 1891) in Levi (1963) was in error. While $A$. jabaquara was illustrated in 1956, A. dubiosus is here illustrated for the first time since its description in 1891 (Fig. 4).

\section{Anelosimus saramacca new species}

Figures 1-3

Type. Male holotype from Voltzberg-Raleighvallen Nature Reserve, Saramacca Province, Suriname [lat. $04^{\circ} 40^{\prime} \mathrm{N}$, long. $56^{\circ} 10^{\prime} \mathrm{W}$ ], Feb. 1982 (D. Smith Trail), with $1 \hat{0}, 59$ paratypes in the Museum of Comparative Zoology; $1 \hat{\sigma}$, $2 q$ paratypes in the Cornell University collection kept at the American Museum of Natural History; 29 paratypes in the British Museum, Natural History.

Description. Female. Carapace orange, lighter on sides. Sternum orange with some black pigment. Legs yellow-white with distal part of articles darker. Dorsum of abdomen with some black and white pigment, sides orange-white. Venter of abdomen with some black and white pigment, black patch anteriorly and behind genital groove, and black patch in front of spinnerets. Eyes subequal in size.

'Museum of Comparative Zoology, Harvard University, Cambridge, Mass. 02138. ${ }^{2}$ Field of Neurobiology and Behavior, Department of Entomology, Cornell University, Ithaca, NY 14853

Manuscript received by the editor September 14, 1982. 
Anterior median eyes their diameter apart, 0.3 diameters from laterals. Posterior median eyes slightly more than their diameter apart, their diameter from laterals. Total length, $3.2 \mathrm{~mm}$. Carapace, 1.3 $\mathrm{mm}$ long, $0.9 \mathrm{~mm}$ wide. First femur, $1.7 \mathrm{~mm}$; patella and tibia, 1.7 $\mathrm{mm}$; metatarsus, $1.3 \mathrm{~mm}$; tarsus, $0.8 \mathrm{~mm}$. Second patella and tibia, $1.4 \mathrm{~mm}$; third, $1.1 \mathrm{~mm}$; fourth, $1.5 \mathrm{~mm}$.

Male. Carapace, sternum orange. Legs yellow-white. Abdomen orange to black. Eyes subequal in size, spacing as in female. Total length, $2.3 \mathrm{~mm}$. Carapace, $0.9 \mathrm{~mm}$ long, $0.6 \mathrm{~mm}$ wide. First femur, $1.2 \mathrm{~mm}$; patella and tibia, $1.3 \mathrm{~mm}$; metatarsus, $0.8 \mathrm{~mm}$; tarsus, 0.6 $\mathrm{mm}$. Second patella and tibia, $1.0 \mathrm{~mm}$; third, $0.8 \mathrm{~mm}$; fourth, 1.0 $\mathrm{mm}$.

Diagnosis. Unlike A. jabaquara and A. dubiosus, Anelosimus saramacca has a short terminal embolus (Fig. 3). The female has an epigynum with a subtriangular depression enclosing a transverse mark; the openings appear posteriorly at the ends of the mark (Figs. 1, 2).

Natural History. A single colony of $A$. saramacca was found in an area of swampy lowland rainforest, approximately midway between Voltz Berg and Van Stockum Berg. The web was similar to that of Anelosimus eximius, but much smaller. It was located in a small sapling, about $30 \mathrm{~cm}$ above the ground. The web consisted of a nearly circular hammock or sheet of silk about $80 \mathrm{~cm}$ in diameter, and a pyramid shaped barrier web about $1 \mathrm{~m}$ tall. In the center of the hammock were retreats consisting of green leaves, some of which were curled.

The colony contained at least 1000 individuals, including males, females and immatures. There were many more adult females than adult males. Large numbers of females with egg cases were found in the leaf retreats. A quick inspection revealed at least 140 females with egg cases.

The egg cases closely resemble those of $A$. eximius and $A$. studiosus - they are pale brown, nearly spherical, and $1.5 \mathrm{~mm}$ in diameter. Several egg cases were collected, but many later proved to be empty or hatched out. Six egg cases containing eggs or embryos had a clutch size of $15.2 \pm 1.8$ eggs.

Like A. eximius, A. saramacca shows cooperative behavior. Several adults and immatures were seen feeding together on large prey items, and the web appears to be a product of cooperative effort. 

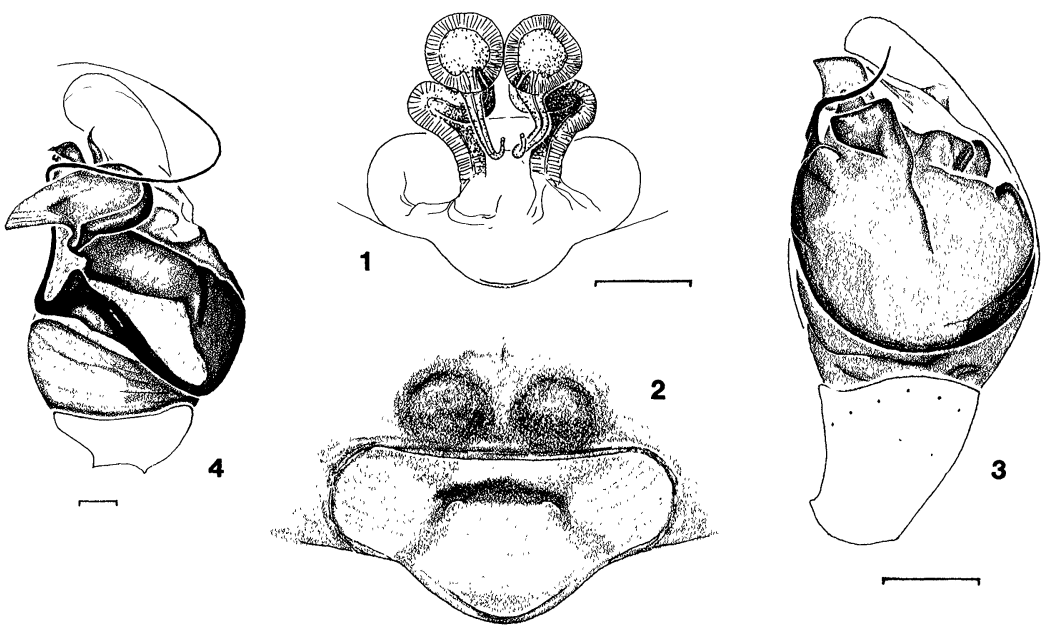

Figs. 1-3. Anelosimus saramacca new species. 1, 2. Epigynum. 1. Dorsal, cleared. 2. Ventral. 3. Left male palpus.

Fig. 4. Anelosimus dubiosus (Keyserling). Left male palpus. Scale lines, $0.1 \mathrm{~mm}$.

\section{Anelosimus dubiosus (Keyserling)}

Figure 4

Theridium dubiosum Keyserling, 1891, 3: 187, pl. 6, fig. 133, ðิ. Male holotype from N. Freiburg (Nova Friburgo, Est. Rio de Janeiro), Brazil in the British Museum, Natural History, reexamined.

Description. Carapace, legs orange. Abdomen white with a dorsal gray band. Total length, $3.4 \mathrm{~mm}$. Carapace, $1.7 \mathrm{~mm}$ long, $1.2 \mathrm{~mm}$ wide. First femur, $2.2 \mathrm{~mm}$; patella and tibia, $2.5 \mathrm{~mm}$; metatarsus, 1.5 $\mathrm{mm}$; tarsus, $0.8 \mathrm{~mm}$. Second patella and tibia, $1.9 \mathrm{~mm}$; third, 1.3 $\mathrm{mm}$; fourth, $1.8 \mathrm{~mm}$.

Note. Anelosimus jabaquara Levi, 1956 is not a synonym of this species as thought in 1963. Anelosimus dubiosus differs by having a much longer filamentous embolus (Fig. 4) than $A$. jabaquara (Levi, 1956, fig. 18) and A. saramacca (Fig. 3).

\section{ACKNOWLEDGMENTS}

The specimens of $A$. saramacca were collected on the Second Cornell Entomology Expedition to Suriname. The cost of this 
expedition was defrayed in part by the Explorers Club, Sigma Xi, the Grace Griswold Memorial Fund, the Cornell Insect Collection, and members of the Cornell Department of Entomology (Dr. William L. Brown, Penelope Kukuk and Maurice Tauber). We also wish to thank the staff of STINASU, the Suriname Nature Conservancy, for their help and cooperation. The senior author thanks the National Science Foundation for grant no. 81-20492 for research and publication support, and Paul Hillyard for the loan of a specimen from the British Museum (Natural History).

\section{ReFerences Cited}

Buskirk, R. 1978. Sociability in the Arachinida. in H. R. Hermann, ed., social INSECTS, Academic Press, 2: 282-367.

Keyserling, E. 1891. Die SPINNen amerikas, Nürnberg, vol. 3.

Levi, H. W. 1956. The spider genera Neottiura and Anelosimus in America (Araneae, Theridiidae). Trans. Amer. Microscop. Soc. 75:333-422.

1963. The American spiders of the genus Anelosimus (Araneae, Theridiidae). Trans. Amer. Microscop. Soc. 82: 30-48.

1967. The theridiid spider fauna of Chile. Bull. Mus. Comp. Zool. 136: $1-20$.

1972. Taxonomic-nomenclatural notes on misplaced theridiid spiders (Araneae, Theridiidae) with observations on Anelosimus. Trans. Amer. Microscop. Soc. 91: 533-538.

1979. in Fowler, H. G. and H. W. Levi, A new quasisocial Anelosimus spider (Araneae, Theridiidae) from Paraguay. Psyche 86: 11-18. 

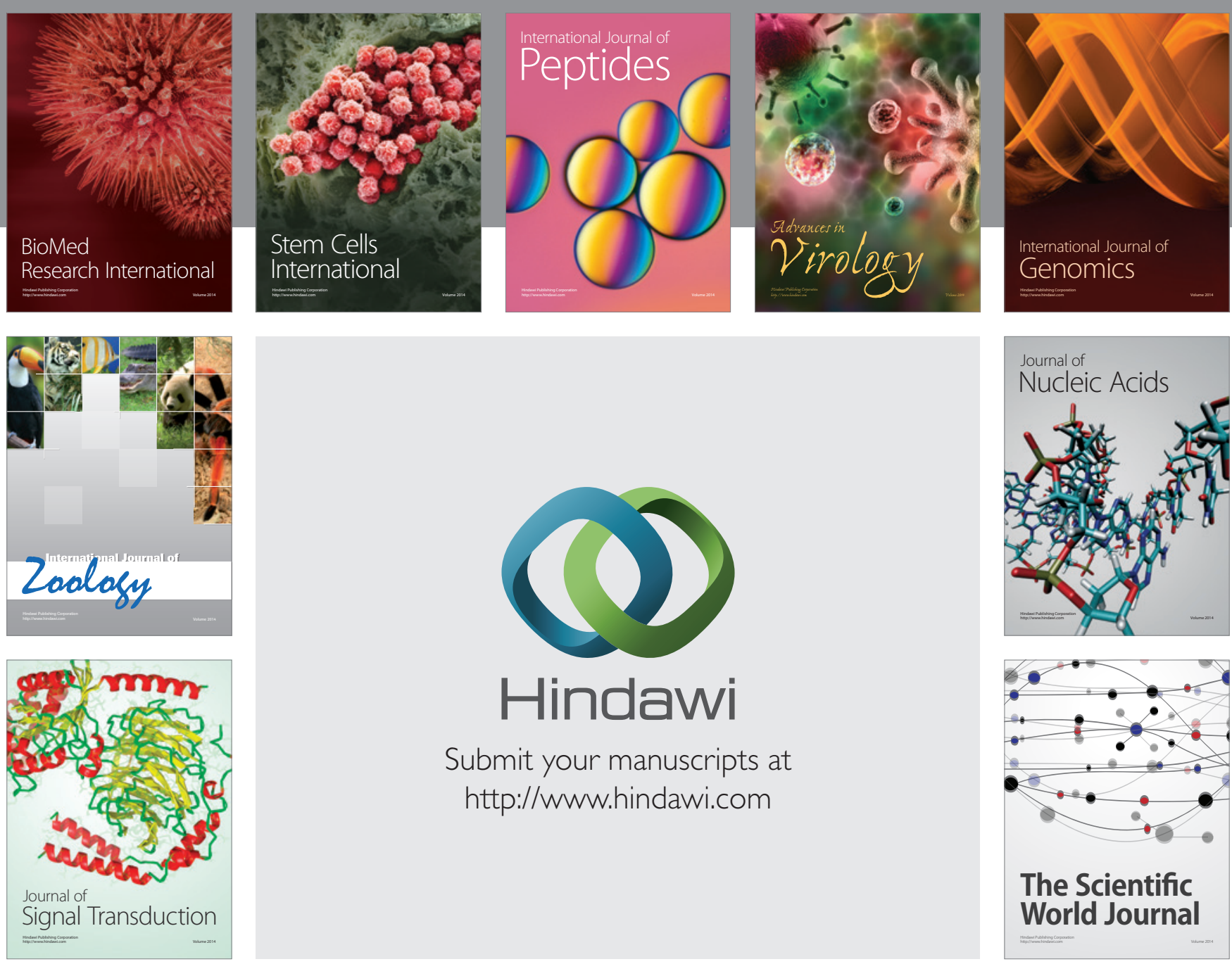

Submit your manuscripts at

http://www.hindawi.com
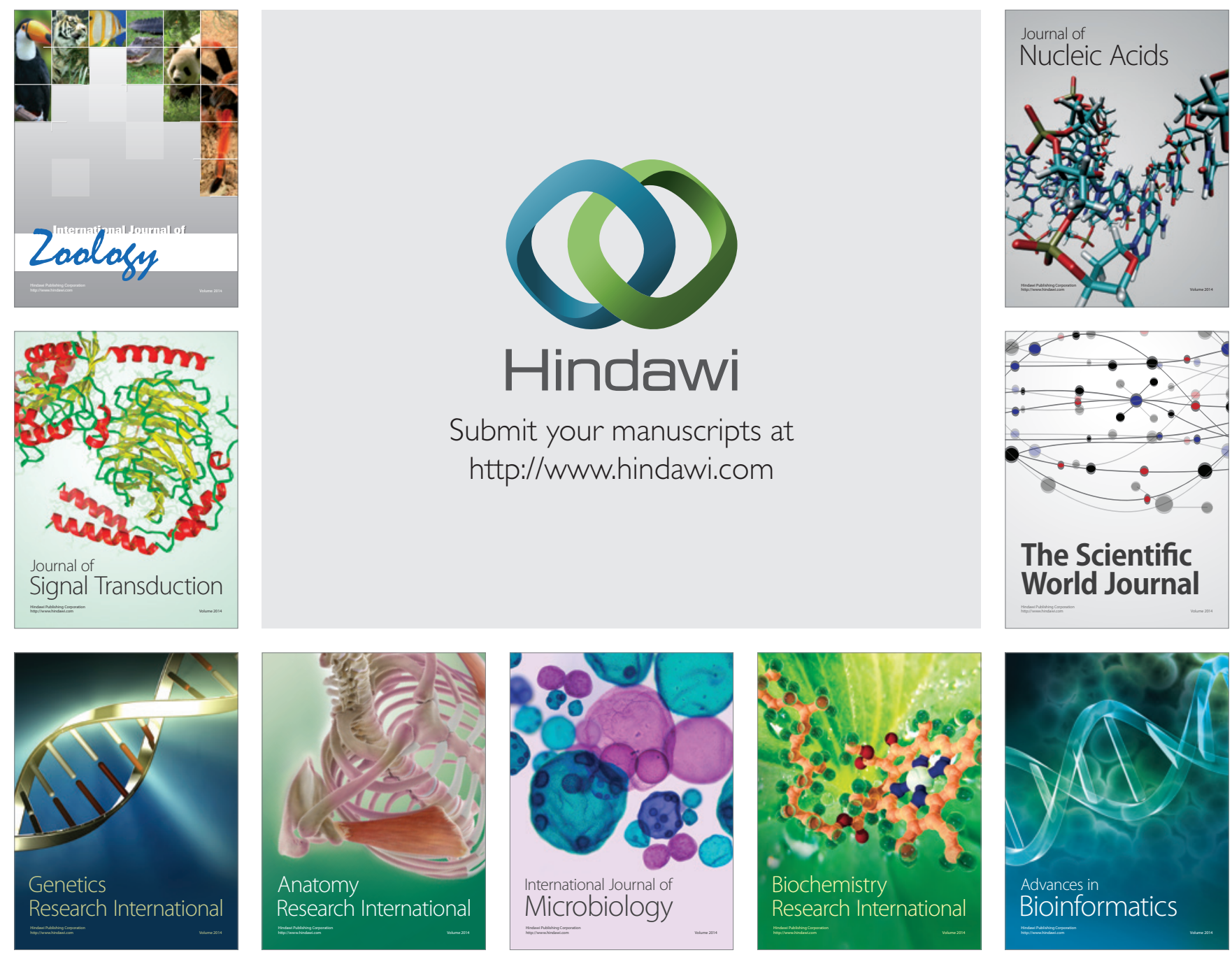

The Scientific World Journal
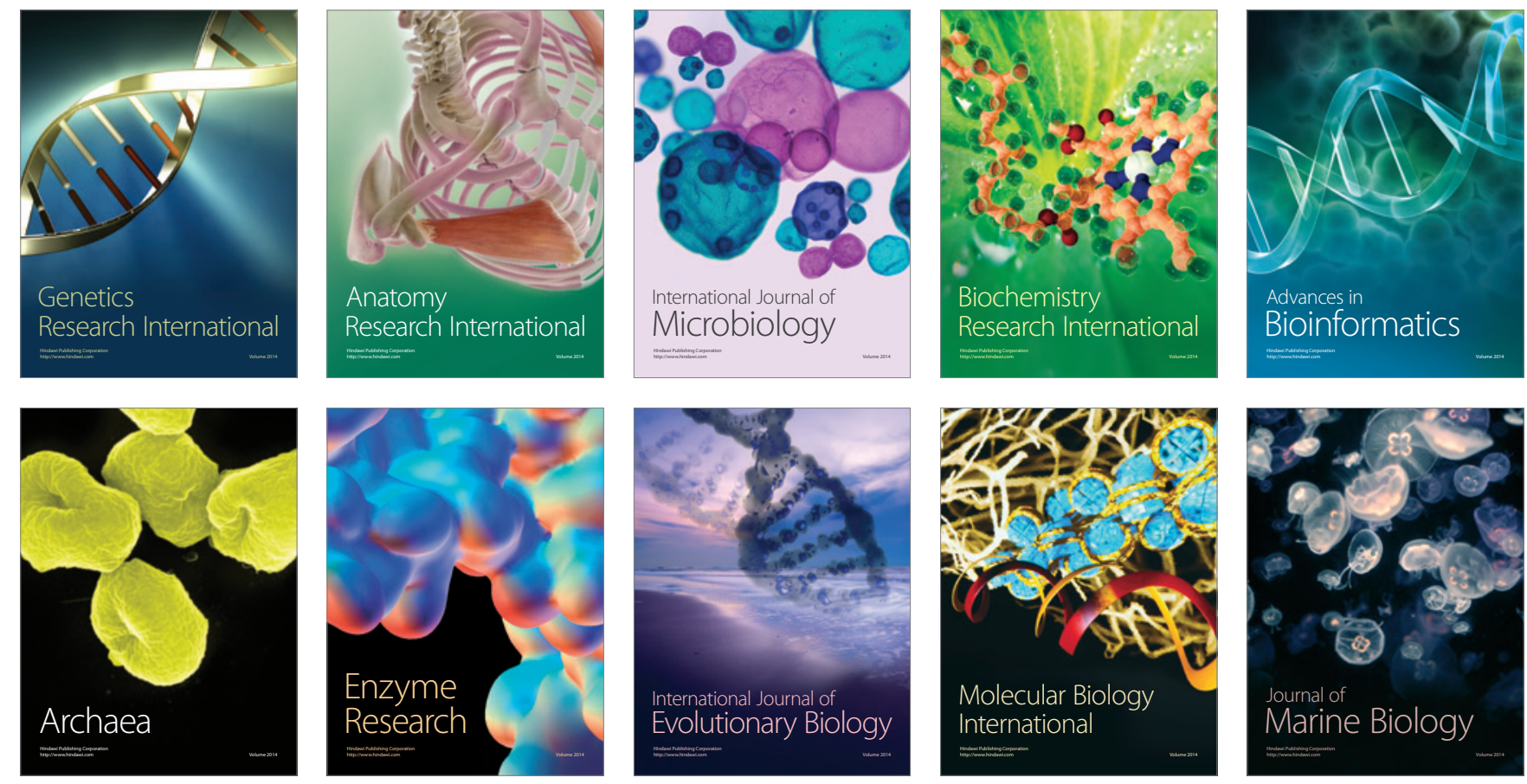